\title{
Group intervention with institutionalised older persons
}

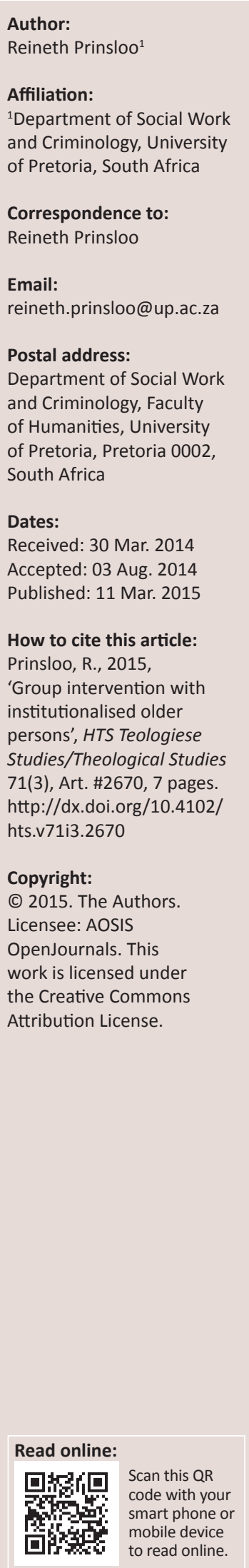

The number of older people in South Africa is increasing. This demands an increase in services by, inter alia, social workers and services by and within religious settings because of the special needs and challenges related to this particular life phase. Group work with older people can assist in creating an awareness of potential and areas for growth as well as assisting with the challenges of growing older. The article discusses a research study with the goal to explore and describe the experiences of group members of a group for institutionalised older persons. A qualitative research study with a collective case study design was utilised to gain insight into the experiences of the individuals within the group and the experiences of the group as a whole. Semi-structured one-on-one interviews were employed as the primary data collection method. Although on a small scale, this research study provides guidelines for group intervention with older people, which allows them to view their lives as meaningful, share personal experiences and problems and realise that they are not alone in their difficulties.

\section{Introduction}

By the end of 2012, the number of older people in South Africa reached more than 4 million, 7.7\% of the total population. This number ranks South Africa as the country with the largest percentage of older persons in Africa (Statistics South Africa 2012:94). In South Africa, an older person may be defined as a person who is, in the case of a male, 65 years of age or older and, in the case of a female, 60 years of age or older (South Africa 2006). The number of older people is expected to increase even further in future. Malan and Dreyer (2009:1 of 9) and Theron (2013:1 of 7) discussed the need for services to the growing number of older people and specifically referred to the responsibility of the church in attending to their needs. This article discusses the use of group work intervention with institutionalised older people and provides research results based on the experiences of group members.

The purpose of this research study was to explore the experiences of a group of older, institutionalised persons whose communication was limited and who had poor relationships with their family members. The younger generations, frequently dual-earner families, have less time and energy to care for elderly parents, and these families are not in a position to fulfil functions such as continuous care and economic support as was the case in the past (Eshleman \& Bulcroft 2010:478; Lombard \& Kruger 2009:124; Schwartz \& Scott 2010:408). Institutional care becomes an option when families are not able to provide daily care and the older family member needs assistance (Santrock 2006:619; Schwartz \& Scott 2010:421; Winningham \& Pike 2007:716). The institution in which this research study was done offers 24-hour nursing care services to frail and aged persons, as well as to vulnerable and psychiatric patients with the same nursing needs. At the time of the study, there were 156 residents within this residential facility, of whom many had little or no contact with their children and other family members. The research question formulated for the purpose of this study reads as follow: What are the experiences of institutionalised older persons of group work?

\section{The phase of older adults}

When categorised as an older person, an individual is placed in the life phase of late adulthood (Berk 2010:444; Kunz 2011:172). The age of 65 and older is usually cited as the dividing age between middle and old age (Passer et al., 2009:591; Santrock in Zastrow \& Kirst-Ashman 2010:587). Later adulthood is the last major segment of the life span. Ageing is an individual process that occurs at different rates in different people (Benokraitis 2011:477; Zastrow \& Kirst-Ashman 2010:587-588). A decline in physical health may invariably accompany old age (Eshleman \& Bulcroft 2010:478; Schwartz \& Scott 2010:416). Stereotyping later adulthood as a life stage of deterioration is however erroneous and sadly is a factor when older adults are being treated as second-class citizens by younger people (Corey \& Corey 2006:400; Kunz 2011:172; Malan \& Dreyer 2009:201; Santrock 2006:616; Zastrow \& Kirst-Ashman 2010:588). Louw and 
Louw (2009:255) reiterate the fact that, although older adults in many communities receive the respect and status they deserve, it is equally true that others often push them aside and even reject them, emphasising the need for services rendered by social and religious organisations.

Ageing is an individual process, experienced in a unique way by each individual. On the one hand, late adulthood is a time of pleasure and tranquillity, when children are grown, life's work is nearly done and responsibilities are lightened; and on the other hand, it often brings concerns about losses, declining physical functions, unwelcome loneliness, and the growing spectre of imminent death (Berk 2007:474; Kunz 2011:177; Schwartz \& Scott 2010:417). Older adults review their life and evaluate its meaning and if the major crises of earlier stages have been successfully resolved the person experiences integrity and a sense of completeness and fulfilment (Passer et al. 2009:591; Robbins, Chatterjee \& Canda 2010:222). Older adults who have not achieved positive outcomes at earlier stages may experience despair, regretting that they had not lived a more fulfilling way (Benokraitis 2011:479; Passer et al. 2009:591). Berk (2007:479) indicates that personal and situational factors often combine to affect psychological wellbeing in late adulthood and that identifying these influences is vital for designing interventions that nurture positive adjustment.

In today's society older people's experiences and wisdom are often not respected, resulting in discrimination and in neglect (Benokraitis 2011:481; Lombard \& Kruger 2009:125; Malan \& Dreyer 2009:203; Robbins et al. 2010:96; Santrock 2006:616). Society needs to develop programs to help the older population maintain their intellectual functioning, and must find additional ways to allow older people to be productive, contributing members to society (Robbins et al. 2010:223; Zastrow \& Kirst-Ashman 2010:604).

\section{Group work with older persons}

Human beings and especially older people need constant interaction with people and the environment (Corey \& Corey 2006:401; Konopka 2006:18). Social and family relationships add to a good quality of life and the group is one of the strongest entities to produce action in human societies (Konopka 2006:18; Victor et al. 2000:407). Working together in small group contexts of 6-12 group members has many benefits, which can ultimately profit all parties involved (Toseland \& Rivas 2009:13). When group members give and receive support from each other, it empowers them to feel useful and accept help and support from others, and the cohesion and group bond within the group give members a sense of belonging and identity. Group work offers members the opportunity to realise that they are not alone in dealing with certain problems and provides members with a place where they can freely express emotions, feelings and thoughts (Corey \& Corey 2006:401; Masson et al. 2012:3; Zastrow 2012:51). The intellectual, emotional and social development of individuals may be furthered through group work activities.
Group work is a productive and cost-effective method of working with older people and can be used to address multiple types of psychosocial and health-related problems (Corey \& Corey 2006; Masson et al. 2012:484-487; Pandya 2010:344). The aging population dramatically increases and can benefit from opportunities that society provides, for example through mutual aid groups (Eshleman \& Bulcroft 2010:481; Lee \& Ayón 2005:24). An older person concerned about what to do after retiring needs to work on finding meaningful and enjoyable activities to become involved in. Every person needs someone to share good times with and to talk about personal difficulties (Winningham \& Pike 2007:717). Group work provides older persons with the opportunity to become involved in enjoyable, meaningful activities and provides them with a safe environment in which they are able to share feelings, thoughts and concerns with other people.

Older people benefit from social support where they experience that they fit in, have self-worth, and experience affection and emotionally fulfilling relationships (Berk 2010:480; Corey \& Corey 2006:401; Santrock 2006:623). Support groups and personal growth or counselling groups can help members to deal with unfinished business from the past, such as guilt about not being a better parent or spouse, or sadness at not having accomplished something during their lifetimes (Kirst-Ashman 2013:334; Masson et al. 2012:485; Zastrow \& Kirst-Ashman 2010:617). Issues such as treatment by children or other family members or their concerns about the future or death are also potential areas for personal work, and members can benefit from simply sharing these concerns and finding support within the group (Masson et al. 2012:484). A common activity in a group for older adults is recalling and reliving different aspects of their lives. This is also an opportunity to identify similar commonalities within the group if focussed on strengths and positive experiences (Berk 2010:476; Rizzo \& Toseland 2008:12).

As individuals get older, they lose some of their roles, for example with retirement one loses work-related roles. However, with age, one also gains roles, such as the grandparent role. Social group work has an important role to play in helping older persons to cope with and adjust both to lost roles and to newly acquired roles (Corey \& Corey 2006:400; Rizzo \& Toseland 2008:8). Older persons are unique, yet share similarities (Toseland \& Rizzo 2004:8). Social workers should take this into account in intervention with older people.

Group work with older persons has several advantages (Masson et al. 2012:485-486; Rizzo \& Toseland 2008:14). Group intervention can provide information about matters such as finances, health and medicine and assist where older people, especially in a residential facility, do not have the resources or influence individually to affect change. Group work may also help to explore new goals in life where members shift their preoccupation from the past to focus more on the present and the future. 


\section{Themes for a group work programme for older people} Depression, positive self-talk and positive thinking

Depression is a common psychiatric disorder in older people and may include feelings of sadness, loneliness, irritability, worthlessness, hopelessness, agitation and guilt accompanied by an array of physical symptoms (Benokraitis 2011:479; Sharp \& Lipsky 2002:1001). Early diagnosis and treatment of depression in older people may improve quality of life and functional status, and may help prevent premature death (Sharp \& Lipsky 2002:1006). Having a positive outlook on life, optimism and effective coping skills are central elements to active ageing (Louw \& Louw 2009:256). Providing group members with helpful hints on changing negative thought patterns can help members develop a more positive frame of reference.

\section{Positive self-esteem}

Adults in later life experience losses in many areas of life and may feel that they have less influence than when they were younger which may lead to lowered self-esteem and loneliness (Malan \& Dreyer 2009:203; Masson et al. 2012:484). Deteriorating health also influences the self-esteem of older people (Santrock 2006:616). Santrock (2006:628) and Kail and Cavanaugh (cited in Zastrow \& Kirst-Ashman 2010:597) emphasise that a positive outlook tends to slow down the ageing process, whereas insecurity, the lack of someone to talk to and negative thinking tend to accelerate the ageing process. In order for older people to feel good about themselves, they need feedback from others indicating that they are worthwhile, competent and respected (Zastrow \& Kirst-Ashman 2010:617). Being in a group with other members, who are able to build them up and encourage one another, provides older persons with a safe place to share their feelings, insecurities and thoughts.

\section{Reminiscence and life review}

Older people often focus on the past, when they were active, were employed, raised children and had good health (Corey \& Corey 2006:409; Masson et al. 2012:484). A valuable activity in groups for older people is to facilitate a process whereby group members can reminisce about different aspects of their lives. Remembering may remind group members of positive aspects and influence self-esteem positively. It may also provide an indication of unresolved issues and emphasise the need for personal work to be done. By remembering and sharing personal experiences and commonalities, older group members may integrate their current life changes within the context of their life history and improve their overall quality of life (Corey \& Corey 2006:410; Winningham \& Pike 2007:720).

\section{Loss and grieving}

By late and even middle adulthood, people typically have lost more friends and loved ones and older people may have even less contact with family members, siblings, or children than in previous years (Passer et al. 2009:595; Masson et al. 2012:484), leading to feelings of isolation and depression (Schwartz \& Scott 2010:417). Jacobs, Masson and Harvill (2006:410-411) indicate that older persons may feel they have less impact on others than they had when they were employed; they had children who sought their advice, and friends who relied on them, which could lead to feelings of lowered self-esteem or alienation. Rizzo and Toseland (2008:10) suggest that although reflections about purpose in life and personal growth wane with age, the importance of group work, in helping older people to view their lives as meaningful and work through losses, increases. Lee and Ayón (2005:38) indicate that some older persons are isolated and lonely even if they live with someone and group membership offers an antidote to this unhealthy situation.

\section{Research methodology Approach, design and sampling}

The goal of this research study was to explore and describe the experiences of group members of a group for institutionalised older persons. The research approach was qualitative and aimed to understand the contribution of group work (Babbie 2011:24; Leedy \& Ormrod in Fouché \& Delport 2011:64; Neuman 2011:38).

The collective case study design was utilised (Bryman 2012:67; De Vaus 2001:220) to understand the unit as a whole. The study sample consisted of a group of seven institutionalised older persons between the ages of 60 and 80 years, who were members of a group for older persons with limited contact with their families and poor relationships with their children.

\section{Data collection}

The experiences of the research participants were explored through using semi-structured interviews with an interview schedule (Greeff 2011:351). Data was analysed by following the steps by Schurink, Fouché and De Vos (2011:403-417). Interviews were audio recorded with the consent of all the research participants. Each recorded interview was transcribed. Memos and short notes were written in the margins of field notes and transcripts (Kreuger \& Neuman, cited in Schurink et al. 2011:409). Significant themes were identified by using colour markers to organise the data. Using a qualitative strategy of inquiry, the results provided a detailed description of the experiences (Creswell 2009:193). A qualitative strategy enabled a perspective of the group as a whole, but also the perspectives and personal experiences of individuals.

Trustworthiness is recognised when findings as closely as possible mirror the meanings as described by the participants (Lincoln \& Guba, cited in Lietz, Langer \& Furman 2006:444). Trustworthiness can be threatened by problems such as reactivity and prejudices by the researcher and the participants (Lietz et al. 2006:444). To ensure that the trustworthiness of the data was not threatened, research 
results were also analysed by the researcher's supervisor and the research support group to validate that the findings were a true reflection of research participants' experiences.

\section{Research results}

For the purpose of data collection, central themes within the context of social work intervention with groups were identified and included in the interview schedule that guided the interviews.

\section{Expectations of the group work series}

\section{Theme 1: Group members had different personal expectations before the group commenced}

Although participants voiced different expectations about the group, they were all slightly unsure about what to expect of the group work series. Participants indicated that they were under the impression that they would speak about different things in the group, that they would be able to complain about certain aspects in their life and that there would be help provided where necessary; '... actually I thought it was going to be fun ... and that I might gain something from it.'

Another participant said that she:

'... did not expect that we would talk many things, but every person who ... I must call it a complaint ... because I also talked about the things that touch me deep inside.'

The participant expected the group work experience to enable her to open up and share personal feelings and thoughts.

During the beginning stages of group work members often worry about what will be expected of them (Toseland \& Rivas 2009:187). It is normal for older group members to be anxious and unsure about what to expect of the group work series at the beginning of the group interaction and a group leader may need to repeat the goal during the course of the intervention (Corey \& Corey 2006:405).

Although group work programmes were conducted at the institution previously and some of the participants were members of these groups, they did not recall significant aspects thereof. Ambivalent feelings are common and should not be seen as a hurdle to achieving the group's goal, as change can be difficult for individuals, and being in the company of individuals that one would normally not spend time with, could lead to feelings of uncertainty or reluctance (Toseland \& Rivas 2009:207).

\section{Structure of the group}

\section{Theme 1: Group members had different experiences of the duration of group sessions}

The duration of group sessions for groups with older people usually lasts 60-90 minutes (Corey \& Corey 2006:404; Masson et al. 2012:487). In the case of this group, meetings took place once per week. Any meeting shorter than one hour does not allow adequate time to carefully discuss matters that were raised and does not enhance productive activity and performance (Zastrow 2012:13). Participants varied in their responses, with two participants indicating that the duration of the sessions suited them perfectly; one participant indicated that she would have made the sessions longer and another participant indicated that she would have preferred if the sessions were a little shorter.

\section{Theme 2: Group members varied in their experience of the size of the group}

The specific group consisted of 7 members. Participants varied in their experience of the size of the group. Responses included that the group size was acceptable; that the group could have been bigger; the group could have been smaller; and that the group membership should have been more selective. The size of a group directly influences members' satisfactions and interactions (Zastrow 2012:12). It is important to keep in mind that the group should be small enough to enable it to achieve its purpose, but also large enough to allow members to have a sustaining experience. The most common number of people in a group appears to be 5-10 for a group highlighting close relationships (Masson et al. 2012:487; Toseland \& Rivas 2009:167). If a group for older persons focuses more on support and sharing, 4-6 members usually works the best, which relates well to the number of members in this specific group.

\section{Theme 3: Rewards and incentives added to a positive experience}

Three of the participants referred to the snacks, which the group worker used as incentives and rewards to encourage members and reward them for their cooperation and involvement in the group work series; 'yes ... the chocolate cake was delicious ...' and 'you gave us biscuits and more'.

Interestingly enough, Hepworth et al. (2010:369) assert that very often creating immediate incentives and tangible rewards, in this case chocolate cake and biscuits, enhance clients' motivations to complete tasks. The cohesion of a group, which is the strength of the bonds that link members to one another, can be accounted for by incentives that are occasionally provided for group membership (Forsyth 2006:14; Toseland \& Rivas 2009:75).

\section{The group leader}

\section{Theme 1: Group members experienced that the group} leader prepared well

All participants indicated that they experienced the group leader as being prepared for every session; '... you have the knowledge, can I put it like that, we have the experience'.

This is an indication of the value of the group experience where the contribution of both the leader and the members result in growth. Group work can be either a success or failure depending on the groundwork that takes place before the group meetings (Drumm 2006:23; Hepworth et al. 2010:273; Zastrow 2012:94). Masson et al. (2012:488) strongly emphasise the need for group leaders of groups for older people to have knowledge of issues accompanying the life phase. 


\section{Theme 2: The group leader treated members in the same way}

All participants indicated that the group leader treated group members well: '.. because ... each individual was treated as if he is ... an absolute person'.

A good leader involves the group, listens to a variety of options and allows members the opportunity to express their feelings and opinions (Becker 2005:44; Zastrow 2012:206). Through performing a caring function, the leader establishes a norm of support, warmth, acceptance and genuineness. Group leaders' behaviours, such as confrontation or criticising, and aspects such as lack of support, play a key role in group dropouts (Becker 2005:46; Smokowski, Rose \& Bacallao 2001 in Hepworth et al. 2010:497). It is important for a group leader to pay attention to all members, but also to see each member as a unique individual.

\section{Theme 3: The group leader created a secure environment}

Participants indicated that they felt '... absolutely safe'.

Group members will not share their thoughts and feelings if they do not perceive the group to be a safe place. It is essential that the group worker facilitates the development of a culture in which group members feel that their experiences and values are of value and they are not alone (Doel 2006:68; Hepworth et al. 2010:504; Masson et al. 2012:387; Toseland \& Rivas 2009:111). When members feel secure in the group, they are more likely to share personal aspects of their lives with each other.

\section{Group dynamics}

\section{Theme 1: Group members experienced group cohesion}

A group provides members with a place where they can freely express emotions, feelings and thoughts (Doel 2006:67). When people feel that they are not alone in their problems, they are more likely to open up and talk about their personal difficulties and worries: '... different people with different problems ... it was good for me to know other people also have problems ...'

Forsyth (2006:14) defines group cohesion as the bonds that link individuals to the group, feelings of attraction for specific group members and the group itself and the degree to which the group members coordinate efforts to achieve goals. Group cohesion ultimately determines the group's unity (Forsyth 2006:30; Hepworth et al. 2010:499). A cohesive group satisfies members' need for affiliation, as some members have unsatisfactory relationships outside of the group.

\section{Theme 2: Group members experienced fellow group members positively}

All participants indicated some sense of positive experience about their fellow group members: 'every person ... I spoke to them, and they spoke to me, chat you know, ...' and 'I actually found it very interesting'.

The nature and value of interpersonal relationships in the group have significant influence on the meaning and value to the members of the group (Zastrow 2012:21). Members interacted with one another in every session and a healthy exchange of information and suggestions took place.

\section{Group sessions}

\section{Theme 1: Members had an understanding of the group goal}

When asked if they could remember what the ultimate goal of the group was, participants indicated that they believed the goal was to focus on relationships, and to speak about the things that bothered them; ' ... it was therapy for our ... relationships with our families and children ...'

Defining goals clearly helps both workers and members focus on what they are attempting to achieve in the group (Toseland \& Rivas 2012:215; Zastrow 2012:110). The purpose of the group validates its existence and the leader and the members should jointly decide on the goal (Becker 2005:34). Campbell (2004:276) mentions that the purpose of the group for older persons will largely depend on how the group defines it. Each of the participants had their own interpretation of the group goal, but as the group series progressed, the group shared a common goal and purpose, focusing primarily on relationships, forgiveness and talking about things that bother them.

\section{Theme 2: Group members were of the opinion that the group met the goal}

Participants believed that the goal of the group was met, and some participants linked their responses to their need to have belonged to such a group and what they had gained from the group in general:

'I needed it for my therapy ... my emotional condition, I think I suffered from depression a little bit, maybe shyness and self-esteem maybe, and improved my relationships and communication.'

An effective group is one that has significant success in achieving its goals; the success and efficacy of the group and its procedures can be measured by the extent to which goals are achieved (Zastrow 2012:110-111).

\section{Theme 3: Group members experienced the individual sessions acceptable}

Participants indicated that they were satisfied with all eight individual sessions conducted during the group work series. By simply describing events, airing feelings and reflecting on efforts to cope, it encouraged self-understanding and aided members to overcome loneliness, isolation and hopelessness (Toseland \& Rivas 2009:23). Although none of the participants identified the same session as being the most valuable, each participant referred to a session that they felt made a lasting impression on them. One participant distinctly remembered the session on forgiveness and relationships:

'I think the day I opened my internet ... because I probably never would have done it. I don't know, but I don't think I would have been able to do it for long as I live.' 
She added: 'the session on forgiveness made me feel very guilty ... that was the most valuable for me, absolutely'.

Santrock (2006:616) refers to lowered self-esteem in this phase because of losses and diminishing health. One participant said:

'... the one about your self-image ... because I always think people criticise me ... and I always worry about what other people think about me ... and so I felt good about my good qualities, you know.'

Sessions provided members with an opportunity to develop new insights, change destructive thought patterns and learn new ways of thinking about challenges that they face. Sessions were planned with the goal of the group as well as individual member's goals in mind, emphasising that a well-formulated goal can provide structure for planning the content of group work.

According to Campbell (2004:277) 'the purpose of being in a group is to make some change that will enhance one's life, reinforce one's ability to cope, and build on existing strengths'. Groups are viewed as especially influential agents of change for the elderly, uniquely suited to the challenges of the ageing process, such as handling loss, shrinking support networks and societal change (Campbell 2004:276). A growth group, which is the type of group that the participants were involved in, offer opportunities for members to become conscious of, grow, and change their thoughts, feelings and behaviours, especially regarding their self-esteem and in relationships with others. Growth groups provide an atmosphere in which group members are able to gain new understandings, experiment with new behaviours, receive feedback and develop as human beings (Toseland \& Rivas 2009:25). Each of the sessions identified made a lasting impact on participants individually, and enabled a change in thoughts and behaviour patterns.

\section{Commonality}

\section{Theme 1: Group members had shared experiences}

Participants indicated that it was beneficial for them to learn that they were not the only ones dealing with certain problems and that others deal with similar problems. As group members share private concerns, thoughts and feelings, they are comforted that others in the group have comparable concerns (Corey \& Corey 2006:247). One participant indicated that she spoke about certain problems in her life for the first time during the group work sessions and that she probably would never have spoken about them, had she not been a member of the group: 'different people have different problems ... it was good for me to know other people also have problems'.

\section{Another participant mentioned:}

\footnotetext{
'... like I'm telling you it was the first time that I could honestly talk about everything that I walk around with and joke and tease about ... things that I keep for myself'.
}

An advantage of group treatment is that members can be helpful to each other, as they provide opportunities for socialisation, validation and normalisation of problems and concerns (Gitterman 2004:99; Toseland \& Rivas 2012:16). This lets members feel less remote and stigmatised and they are more likely to listen to one another's views and suggestions. Rizzo and Toseland (2008:14) mention that one of the advantages for older persons who participate in a group is the consensual validation and affirmation of one's experiences.

\section{Recommendations}

The recommendations formulated about the research results apply to service delivery and institutions for older people and on the importance of group work. The growing population of older people necessitates service delivery to address the challenges and needs accompanying this phase in their lives, and governmental, private and religious organisations have an obligation to reach out and contribute to the wellbeing of this age group. Group work can help older people to view their lives as meaningful and provide them with an opportunity to deal with unfinished business from the past.

However, group members in this age group should be chosen selectively, members should be in the same age group and share a common problem. A group leader should make members aware of the ultimate purpose of the group work series to help them define and understand what is expected of them. The group leader must allow for the development and define the expectations during the beginning stages of the group. The duration of group work sessions for older persons should last for about $45-90$ minutes. This will provide adequate time for sharing and interacting, and prevent members from becoming bored, irritated or frustrated with one another or the group leader. Rewards and incentives should be given to members occasionally to keep them motivated and encouraged and can be used to congratulate members on the achievement of goals or personal milestones. Service providers working with older persons should recognise that group work is an extremely valuable method for intervention because of the importance for the social group.

For the purposes of future research, it is recommended that an evaluation of the contribution of a group work intervention programme should be done again at a later stage to assess the long-term influence. Standardised measuring instruments for life skills themes such as self-esteem, relationships with significant others, assertiveness, communication and conflict management can be used to do quantitative research on the impact of group work intervention.

This study collected valuable information on the personal experiences of a group of institutionalised older persons during group work; however, the participants were limited to a single culture, race and gender. All the participants were Afrikaans white females, with the exception of one respondent who grew up in an English household. Because of 
the small sample size, it is impossible to generalise about the experiences older persons have of group work. This research study, although on a very small scale, aimed to address the need for evaluation of the contribution of group work through a formal research process, in the lives of a group of institutionalised older persons, but more research should be conducted to fully determine the contribution of group work on the lives of institutionalised older persons.

\section{Acknowledgements}

The group work program for older persons was presented by a final year Bachelor of Social Work student, MS Elmi Pretorius, for the purpose of her Social Work Practice 400 module. She collected the research results and prepared a research report under the author's supervision for the Social Work Theory 455 module.

\section{Competing interests}

The author declares that she has no financial or personal relationship(s) that may have inappropriately influenced her in writing this article.

\section{References}

Babbie, E., 2011, Introduction to social research, 5th edn., Wadsworth/Thomson Learning, Belmont.

Becker, L., 2005, Working with groups, Oxford University Press, Southern Africa.

Benokraitis, N.V., 2011, Marriages \& families: Changes, choices and constraints, 7th edn., Pearson, Boston.

Berk, L.E., 2007, Development through the lifespan, 4th edn., Pearson Education, Inc., Boston.

Berk, L.E., 2010, Exploring lifespan development, 2nd edn., Allyn \& Bacon, Boston.

Bryman, A., 2012, Social research methods, 4th edn., Oxford University Press, New York.

Campbell, R., 2004, 'Groups for Older Adults', in C.D. Garvin, L.M. Gutiérrez \& M.J. Galinsky (eds.), Handbook of social work with groups, pp. 275-291, The Guilford Press, New York.

Corey, M.S. \& Corey, G., 2006, Groups: Process and practice, 7th edn., Thomson Brooks/Cole, Belmont.

Creswell, J.W., 2009, Research design: qualitative, quantitative \& mixed methods approaches, 3rd edn., SAGE Publications Inc., Thousand Oaks.

De Vaus, D., 2001, Research design in social research, SAGE Publication Ltd, London.

De Vos, A.S., Strydom, H., Fouché, C.B. \& Delport, C.S.L. (eds.), 2011, Research at grass roots: For the social sciences and human services profession, 4th edn., Van Schaik, Pretoria.

Doel, M., 2006, Using groupwork, Routledge, London.

Drumm, K., 2006, 'The essential power of group work', Social Work with Groups 29(2/3), 17-31. http://dx.doi.org/10.1300/J009v29n02_02

Eshleman, J.R. \& Bulcroft, R.A., 2010, The family, 12th edn., Allyn \& Bacon, Boston.

Forsyth, D.R., 2006, Group dynamics, 4th edn., Thomson Wadsworth, Belmont.

Fouché, C.B. \& Delport, C.S.L., 2011, 'Introduction to the research process', in A.S. De Vos, H. Strydom, C.B. Fouché \& C.S.L. Delport (eds.), Research at grass roots: For the social sciences and human services profession, 4th edn., pp. 61-76, Van Schaik, Pretoria.

Gitterman, A., 2004, 'The mutual aid model', in C.D. Garvin, L.M. Gutiérrez \& M.J. Galinsky (eds.), Handbook of social work with groups, pp. 93-110, The Guilford Press, New York.

Greeff, M., 2011, 'Information collection: Interviewing', in A.S. De Vos, H. Strydom, C.B. Fouché \& C.S.L. Delport (eds.), Research at grass roots: For the social sciences and human services profession, 4th edn., pp. 341-375, Van Schaik, Pretoria.
Hepworth, D.H., Rooney, R.H., Rooney, G.D., Strom-Gottfried, K. \& Larsen, J., 2010, Direct social work practice: Theory and skills, 8th edn., Brooks/Cole, 2010, Direct

Kirst-Ashman, K.K., 2013, Introduction to social work and social welfare: Critical thinking perspectives, 4th edn., Brooks/Cole, Belmont.

Jacobs, E., Masson, R.L. \& Harvill, R.L., 2006, Group counselling: Strategies \& skills, 5th edn., Thomson Brooks/Cole, Belmont.

Konopka, G., 2006, 'The significance of social work based on ethical values', Social Work with Groups 28(3-4), 17-28. http://dx.doi.org/10.1300/J009v28n03_03

Kunz, J., 2011, Think marriages and families, Pearson, Boston.

Lee, C.D. \& Ayón, C., 2005, 'The power of groups for older adults: A comparative study of European American and Latino senior mutual aid groups', Social Work with Groups 28(2), 23-39. http://dx.doi.org/10.1300/J009v28n02 03

Lietz, C.A., Langer, C.L. \& Furman, R., 2006, 'Establishing trustworthiness in qualitative research in social work: Implications from a study regarding spirituality', Qualitative Social Work 5(4), 441-458. http://dx.doi.org/10.1177/1473325006070288

Lombard, A. \& Kruger, E., 2009, 'Older persons: The case of South Africa', Ageing International 34, 119-135.

Louw, D. \& Louw, A., 2009, Adult development and ageing, University of Bloemfontein, Bloemfontein.

Malan, E. \& Dreyer, Y., 2009, 'Multidissiplinêre beskouinge op veroudering vanuit 'n pastorale perspektief', HTS Teologiese Studies/Theological Studies 65(1), Art. \#182, 9 pages.

Masson, R.L., Jacobs, E., Harvill, R.L. \& Schimmel, C.J., 2012, Group counselling: Interventions and techniques, 7th edn., Brooks/Cole CENGAGE Learning, Belmont.

Neuman, W.L., 2011, Social research methods: Qualitative and quantitative approaches, 7th edn., Allyn \& Bacon, Boston.

Pandya, V., 2010, An evidence base for group work with older adults living in the community', Social Work with Groups 33(4), 323-349. http://dx.doi.org/10.108 0/01609513.2010.487177

Passer, M., Smith, R., Holt, N., Bremner, A., Sutherland, E. \& Vliek, M., 2009, Psychology: The science of mind and behaviour, McGraw-Hill Higher Education, Maidenhead.

Robbins, S.P., Chatterjee, P. \& Canda, E.R., 2010, Contemporary human behaviour theory: A critical perspective for social work, 2nd edn., Pearson, Boston.

Rizzo, V.M. \& Toseland, R.W., 2008, 'What's different about working with older people in groups?', Journal of Gerontological Social Work 44(1/2), 5-23.

Santrock, J.W., 2006, Life-span development, 10th edn., McGraw-Hill, New York.

Schurink, W., Fouché, C.B. \& De Vos, A.S., 2011, 'Qualitative data analysis and interpretation', in A.S. De Vos, H. Strydom, C.B. Fouché \& C.S.L. Delport, (eds.) Research at grass roots: For the social sciences and human services profession, 4th edn., pp. 397-424, Van Schaik, Pretoria.

Schwartz, M.A. \& Scott, B.M., 2010, Marriages and families, 6th edn., Prentice Hall, Upper Saddle River.

Sharp, L.K. \& Lipsky, M.S., 2002, 'Screening for depression across the lifespan: a review of measures for use in primary care settings', American Family Physician 66(6) of measures

South Africa, 2006, 'Older persons Act no. 13', Government Gazette 497, 29346.

Statistics South Africa, 2012, 'Social profile of vulnerable groups in South Africa 20022012', Statistics South Africa, Pretoria.

Theron, P.M., 2013, 'Practical theologians' calling to serve in the field of gerontology', HTS Teologiese Studies/Theological Studies 69(2), Art. \#1942, 7 pages.

Toseland, R.W. \& Rizzo, V.M. 2004, 'What's different about working with older people in groups?', in R. Salmon \& R. Graziano (eds.), Group work and aging: Issues in practice, research and education, pp. 5-24, The Haworth Press, Binghamton.

Toseland, R.W. \& Rivas, R.F., 2009, An introduction to group work practice, 6th edn., Pearson Allyn \& Bacon, Boston.

Toseland, R.W. \& Rivas, R.F., 2012, An introduction to group work practice, 7th edn., Pearson Allyn \& Bacon, Boston.

Victor, C., Scambler, S., Bond, J. \& Bowling, A., 2000, 'Being alone in later life: loneliness, social isolation and living alone', Reviews in Clinical Gerontology 10 (4) 407-417. http://dx.doi.org/10.1017/S0959259800104101

Winningham, R.G. \& Pike, N.L., 2007, 'A cognitive intervention to enhance institutionalized older adults' social support networks and decrease loneliness', Aging \& Mental Health 11(6), 716-721. http://dx.doi.org/10.1080/ 13607860701366228

Zastrow, C.H., 2012, Social work with groups: A comprehensive work text, 8th edn., Brooks/Cole, Belmont.

Zastrow, C.H. \& Kirst-Ashman, K.K., 2010, Understanding human behaviour and the social environment, 8 th edn., Brooks/Cole, Belmont. 